\title{
Knowledge on dental trauma and orthodontic tooth movement held by a group of orthodontists
}

\section{Pedro Marcelo Tondelli(a) Marcos Rogério de Mendonça( ${ }^{(b)}$ Osmar Aparecido Cuoghi(b) Alex Luiz Pozzobon Pereira ${ }^{(a)}$ Mauro Carlos Agner Busato ${ }^{(a)}$}

(a) PhD student in Orthodontics, Faculdade de Odontologia de Araçatuba, Unesp - Univ Estadual Paulista, Araçatuba, SP, Brazil.

(b) Assistant Professor of Orthodontics, Department of Pediatric and Community Dentistry, Faculdade de Odontologia de Araçatuba, Unesp - Univ Estadual Paulista, Araçatuba, SP, Brazil.

\section{Corresponding author:}

Pedro Marcelo Tondelli

Disciplina de Ortodontia - Faculdade de

Odontologia de Araçatuba - UNESP

Rua José Bonifácio, 1193

Araçatuba - SP - Brazil

CEP: 16015-050

E-mail: tondelli.ortodontia@hotmail.com

Received for publication on Nov 06, 2008 Accepted for publication on Mar 23, 2009

\begin{abstract}
The objective of this work was to assess the knowledge about orthodontic tooth movement and dental trauma held by a group of orthodontists in specific areas of Brazil. For this purpose, 166 questionnaires with 15 objective questions about this subject were distributed. One hundred and five questionnaires were properly filled and collected after 30 days. It was concluded that, except for avulsion, the knowledge on dental injuries held by the professionals interviewed was considered unsatisfactory, and about $40 \%$ of them were not acquainted with the recommendations for the orthodontic movement of traumatized teeth.
\end{abstract}

Descriptors: Tooth injuries; Tooth movement; Orthodontics.

\section{Introduction}

Even though both Dentistry and Orthodontics have presented continuous improvement, when one or more teeth are submitted to a dental trauma, the treatment of malocclusion can be completely altered. ${ }^{1}$

Previous detailed evaluation of the root morphology, at the beginning of the orthodontic treatment, is a requirement emphasized by Levander, Malmgren $^{2}$ (1988). These authors advised a thorough examination of the root outline, observing the occurrence of any root resorptions, surface concavities and malformations, since teeth with these characteristics may be severely reabsorbed during treatment. Malmgren et al. ${ }^{3}$ (1982) stated that, when facing evident root resorptions, the treatment purposes must be reviewed.

However, dental movement induced on traumatized teeth still receives inadequate attention by the specialized literature. Examining the related literature, many different publications about the topic can be found which do not contribute to the development of a safe protocol for clinical procedures. Recently, Kindelan et al. ${ }^{4}$ (2008) published a review about dental trauma and its influence on the management of orthodontic treatment, contributing with the currently best evidence on the topic.

The objective of the present study was to assess the knowledge about dental trauma and orthodontic movement of traumatized teeth held by general dentists and specialists in Orthodontics in specific areas of Brazil, and, in doing so, to collect information which may help develop specific studies about the topic and enable safe clinical procedures. 


\section{Material and Methods}

In order to carry out the present study, a threepart questionnaire was elaborated (Figure 1). The first part aimed at outlining the interviewees' academic and professional profile, the second part was concerned to specific questions about dental trauma, and the third part was about orthodontic movement of traumatized teeth.

An amount of 166 questionnaires were distributed. The number of professionals who answered them was 105 (63.25\%), 66 male and 39 female, with ages varying from 24 to 76 years. Seventy four professionals with a specialization degree, 17 with a MSc degree and 14 with a PhD degree participated in the survey. The year of conclusion of the courses they took ranged between 1970 and 2007, thus demonstrating the dissimilarity of the sample. This research was approved by the Committee of Ethics in Human Research, Dental School of Araçatuba,
Univ. Estadual Paulista (UNESP).

The questionnaire contained 3 questions dealing with the professional and academic profile of the participants and 12 specific questions about dental trauma and orthodontic movement of traumatized teeth. These questions were conceived by the authors and submitted to the evaluation of $2 \mathrm{MSc}$ and $\mathrm{PhD}$ students in orthodontics, as well as $5 \mathrm{PhD}$ professors, who also contributed with suggestions. In addition, a pilot study was conducted with 53 orthodontic specialists.

The questionnaires were handed by the authors to 166 orthodontic specialists, at their own dental offices. One hundred and five questionnaires were answered and returned, of which 42 were answered immediately after they were received by the participant, and 63 were collected by the authors after a period varying from 10 to 30 days.

The questionnaires were gathered in a previously

PART 1 - PROFESSIONAL AND ACADEMIC PROFILE

1. Age: Gender: ( ) male ( ) female

2. Which of these courses did you take?
( ) Specialization
Hours:
Months:
Year of conclusion:
( ) MSC
Hours:
Months:
Year of conclusion:
( ) PhD
Hours:
Months:
Year of conclusion:

3. Do you practice exclusively Orthodontics in your dental office?

( ) yes

( ) no

PART 2 - DENTAL TRAUMA DATA

1. A tooth displacement in a non-axial direction that is accompanied by comminution (crushing) or alveolar socket fracture is classified as:
( ) concussion
( ) subluxation
( ) luxation
( ) avulsion
( ) none
( ) I don't know

2. An injury to the tooth supporting structures with an increase in mobility and without tooth displacement is classified as:
( ) concussion
( ) subluxation
( ) luxation
( ) avulsion
( ) none
( ) I don't know

3. An injury to the tooth supporting structures without increasing tooth mobility or displacement but with significant sensibility to the percurssion, is classified as:
( ) concussion
( ) subluxation
( ) luxation
( ) avulsion
( ) none
( ) I don't know

4. A complete displacement of the tooth out of its alveolus is classified as:
( ) concussion
( ) subluxation
( ) luxation
( ) avulsion
( ) none
( ) I don't know

Figure 1 - Questionnaire used in the study to assess the knowledge on dental trauma and orthodontic movement of traumatized teeth held by a group of orthodontists. [continued on next page] 


\section{PART 3 - DENTAL TRAUMA VERSUS ORTHODONTICS DATA}

1. In your opinion, which of the following is the least harmful movement to upper incisors that have suffered a lateral luxation trauma? (choose only one alternative)
( ) intrusion
( ) extrusion
( ) torque
( ) rotation
( ) translation
( ) inclination
( ) none
( ) I don't know

2. In a case of first premolars extraction for anterior-superior retraction, do you change your procedure or treatment plan after observing a severe lateral luxation trauma to the upper incisors?
( ) yes
( ) no

3. In your opinion, which of the following procedures should be taken in patients who have suffered a slight dental trauma during orthodontic treatment?
( ) continue the treatment normally
( ) wait for a period of 30 days
( ) wait for a period of 3 months
( ) wait for a period of 6 months
( ) wait for a period of 1 year
( ) don't know
( ) other. Please, specify

4. In your opinion, which of the following procedures should be taken in patients who have suffered a severe dental trauma during orthodontic treatment?
( ) continue the treatment normally
( ) wait for a period of 30 days
( ) wait for a period of 3 months
( ) wait for a period of 6 months
( ) wait for a period of 1 year
( ) don't know
( ) other. Please, specify

5. Do you continue taking radiographs of theses traumatized teeth during treatment?
( ) yes
( ) no

6. In your opinion, can a tooth with root fracture in the apical third be moved normally?
( ) yes
( ) no

7. In your opinion, can traumatized teeth suffer a greater root resorption with induced dental movement?
( ) yes
( ) no

8. In your opinion, can the intensity of the trauma influence the prognosis of induced dental movement?
( ) yes
( ) no

Figure 1 [continued] - Questionnaire used in the study to assess the knowledge on dental trauma and orthodontic movement of traumatized teeth held by a group of orthodontists.

stipulated time limit of 30 days. The collected data from the 105 questionnaires answered were processed using the Epi Info 2000 statistical program, specific field research software, which provided a descriptive analysis of the data.

A template for the answers was developed based on texts widely applied in Dentistry teaching.

The work of Andreasen et al. ${ }^{5}$ (2007), referring to dental trauma, the chapter written by Malmgren, Malmgren $^{1}$ (2007) about orthodontic movement of traumatized teeth, and the work of Proffit, Fields ${ }^{6}$
(2002) were the main sources used for the development of the above-mentioned template.

\section{Results}

In order to establish the professionals' knowledge final average about dental trauma, the answers to the questions in the second part of the questionnaire were used because they were specifically related to that subject. As a result, $62.85 \%$ of the professionals chose the right answers and $37.15 \%$ chose the wrong ones (Table 1). 
The questions in the third part of the questionnaire were used to establish the professionals' knowledge final average about orthodontic movement of traumatized teeth. As a result, $59.75 \%$ of the professionals chose the right answers and $40.25 \%$ chose the wrong ones (Table 2).

\section{Discussion}

The definitions and clinical significance of dentoalveolar traumatisms presented by Andreasen et al. ${ }^{5}$ (2007) are widely accepted in Dentistry teaching. Using the concepts put forth by those authors as a reference, almost all the respondents know how to define avulsion correctly $(96.2 \%)$.

In contrast, only half of the respondents know the correct definitions of concussion, subluxation and luxation. Thus, it was observed that many professionals have difficulty in diagnosing the different types of dental trauma, which should be treated differently and exert different influences on orthodontic treatment.

The right answer rate was $56.2 \%$ for subluxation and $45.7 \%$ for luxation. Since different traumatisms

Table 1 - Percental distribution of right and wrong answers to the second part of the questionnaire, and final averages.

\begin{tabular}{l|c|c}
\hline \multicolumn{1}{c|}{ Question N. (Part 2) } & Right \% & Wrong \% \\
\hline 1 - Luxation & 45.7 & 54.3 \\
\hline 2 - Subluxation & 56.2 & 43.8 \\
\hline 3 - Concussion & 53.3 & 46.7 \\
\hline 4 - Avulsion & 96.2 & 3.8 \\
\hline Total & $62.85 \%$ & $37.15 \%$ \\
\hline
\end{tabular}

produce different effects on teeth and supporting tissues, they require different care. Thus, the observed percentage of error seems to be exposing a situation where patients are submitted to empiric procedures or procedures without proper scientific support. $\mathrm{Pa}$ tients vulnerability to this lack of knowledge on the part of some professionals is a matter for concern.

The relevance of investigating the procedures taken by professionals when facing dental trauma is not only related to discussing specific shortcomings in the classroom, but also to stimulating scientific research that may establish safe procedures to be adopted by professionals. Kindelan et al. ${ }^{4}$ (2008) have contributed with the best evidence currently available for the management of the orthodontic patient who has sustained dental trauma.

According to Malmgren, Malmgren ${ }^{1}$ (2007), there is no simple explanation for the reasons that lead to root resorption, but dental trauma is an etiological factor consistently reported by the literature. In fact, several authors ${ }^{4,7-17}$ refer to dental trauma as a factor which predisposes the teeth to root resorptions.

Brin et al. ${ }^{14}$ (1991) stated that teeth adjacent to a directly traumatized tooth suffer a lesser degree of root resorption than the traumatized one, but higher than the teeth submitted only to orthodontic movement, without previous trauma. Nevertheless, teeth which present root resorption before orthodontic movement will surely present greater resorption during treatment. ${ }^{2,3}$

A dissimilarity of opinions arose when the professionals were asked which would be the least
Table 2 - Percental distribution of right and wrong answers to the third part of the questionnaire, and final averages.

\begin{tabular}{l|l|c}
\hline \multicolumn{1}{c|}{ Question N. (Part 3) } & Right $\%$ & Wrong \% \\
\hline 1 - Extrusion & 20 & 80 \\
\hline 2 - Yes, I change the procedure & 81.9 & 18.1 \\
\hline 3 - I wait for 3 months & 36.2 & 63.8 \\
\hline 4 - I wait for 6 months & 31.4 & 68.6 \\
\hline 5 - Yes, I continue taking radiographs & 97.1 & 2.9 \\
\hline 6 - Yes, fractured teeth can be moved & 36.2 & 63.8 \\
\hline 7 - Yes, traumatized teeth can suffer greater root resorption & 80 & 20 \\
\hline 8 - Yes, the severity of the trauma can influence prognosis & 95.2 & 4.8 \\
\hline Total & $59.75 \%$ & $40.25 \%$ \\
\hline
\end{tabular}


harmful movement on traumatized upper incisors. Of all the respondents, $24.8 \%$ affirmed that they did not know the right answer and $5.7 \%$ left the question blank. In other words, the lack of knowledge amounted to $30.5 \%$. The movement which produces minor biological stimulus, with absence or minimal areas of compression of the periodontal ligament is extrusion. ${ }^{6}$

One of the protocols for the treatment of intrusive luxation includes an extrusive orthodontic movement for traumatic tooth repositioning. ${ }^{10-12,18-21}$ When traumatically intruded teeth do not present mobility, surgical luxation, previously to orthodontic extrusion, could be helpful to enable the movement without compromising the anchorage units by causing their intrusion. ${ }^{10-12}$

In cases of intrusive luxation of about $3 \mathrm{~mm}$ and when the teeth present open apexes, it is possible to await spontaneous eruption. ${ }^{19,20}$ When this does not happen, however, orthodontic repositioning is indicated, observing pulp vitality. In teeth with complete root formation, surgical or orthodontic repositioning must be adopted as soon as possible, together with an endodontic treatment with calcium hydroxide. Otherwise, the dental pulp will become necrotic. ${ }^{19}$

The relevance of this topic increases when the professional faces a traumatized tooth during the orthodontic treatment, a fact which may change the initial planning completely.

In our sample, $81.9 \%$ of the professionals would change their procedure in a case of premolars extraction that suffered a severe trauma on the incisors, and among these professionals, $83.7 \%$ would interrupt the treatment for a repair period and then resume it later accepting limitations to the initial purposes.

Regarding slight trauma, $38.1 \%$ of the professionals reported that they would wait for a period of 30 days, and $36.2 \%$ would wait for 90 days before resuming treatment.

Based on literature data, before subjecting a tooth to orthodontic movement, a repair period of 3 to 5 months ${ }^{1,3,4}$ is recommended in cases of slight dental trauma such as concussion and subluxation. The shortest period chosen by the minority of our sample (1 month) is far shorter the period recom- mended by the authors, and the longest period ( 3 months), chosen by the majority of our sample is closer to the shortest period recommended by literature. In others words, in our sample, the professionals who chose to wait the longest chose the minimal period recommended by literature.

In the case of severe trauma such as luxation, a period of 6 months to 1 year is recommended. In the case of a fractured root, the recommended period is 1 to 2 years, and in the case of a reimplanted tooth, at least 1 year. ${ }^{1,4}$ In our sample, after observing severe dental trauma, $41 \%$ would wait for 3 months and $31.4 \%$ would wait for 6 months.

Besides this lack of consensus, the time period the majority of the respondents stated for the respective traumatisms was inferior to the period recommended by literature, thus increasing the chances of root resorption.

When a root fracture is detected, Flores et al. ${ }^{22}$ (2007) recommend a semi-rigid immobilization for 4 weeks and radiographic control for up to 5 years. In these cases, repair may occur through the fusion of the fractured segment, in which case the tooth preserves its original size, or through the interposition of conjunctive tissue between the fragments. In both cases, the tooth could be moved after a repair period of 1 to 2 years, ${ }^{1,4}$ though, in the case of fragment separation, the movement would be induced on a tooth with a shorter root. Nonetheless, only $36.2 \%$ of the participants answered correctly and $63.8 \%$ affirmed that a tooth with this type of fracture cannot be moved.

It seems that there is deep concern among the professionals in relation to the risks inherent to dental trauma during orthodontic treatment, since $97.1 \%$ of them answered that they would adopt a follow-up radiographic control during the treatment, and $95.2 \%$ believe that the intensity of the trauma may influence the prognosis of the induced dental movement.

A trimestrial radiographic control ${ }^{15,16}$ of the traumatized tooth has been suggested and, as recommended by Flores et al. ${ }^{19,22,23}$ (2007), in the case of concussion, a follow-up period of up to 1 year and, in more severe traumatisms, up to 5 -years should be observed. When minimal root resorption is detect- 
ed during orthodontic treatment, there is low risk of severe resorption taking place. ${ }^{15,16}$ On the other hand, when extensive resorption is observed, the treatment should be interrupted and the possibility of discontinuing or limiting the procedures should be considered. Inflammatory root resorption may be radiographically detected within 3 weeks of its onset, and ankylosis may be so within a period of 2 months to 1 year. $^{1}$

When the orthodontist is prepared to deal with dental trauma, whether by recognizing it early on and considering it in his treatment plan, or by diagnosing it when faced with an emergency, the prognosis will certainly be much more favorable, thus minimizing physical, emotional and aesthetic discomfort.

In 2000, a retrospective study ${ }^{24}$ reported that $50 \%$ of facial fractures occurred in the ages ranging from 11 to 30 years. Men were more affected than women (ratio of $4.69: 1$ ), and $6.41 \%$ had dentoalveolar fractures. Continuous long-term collection of data regarding the epidemiology of maxillofacial fractures is important because it provides necessary information for the development and evaluation of preventive measures for reducing the incidence of facial injuries.

The incidence of upper incisors trauma is related to an increase of overjet, ${ }^{1,13}$ doubling the incidence with an overjet of 3 to $6 \mathrm{~mm}$ and tripling it when overjet is superior to $6 \mathrm{~mm} .{ }^{1}$ Some of the sequelae of dental trauma are: ankylosis, external root resorption, pulp necrosis ${ }^{10-12}$ pulp obliteration, marginal bone loss, ${ }^{12}$ alveolar fracture, ${ }^{1,22}$ crown fracture,

\section{References}

1. Malmgren O, Malmgren B. Orthodontic management of the traumatized teeth. In: Andreasen JO, Andreasen FM, Andersson L, editors. Textbook and color atlas of traumatic injuries to the teeth. $4^{\text {th }}$ ed. Oxford: Blackwell Munksgaard; 2007. p. 699-715.

2. Levander E, Malmgren O. Evaluation of the risk of root resorption during orthodontic treatment: a study of upper incisors. Eur J Orthod. 1988;10(1):30-8.

3. Malmgren O, Goldson L, Hill C, Orwin A, Petrini L, Lundberg M. Root resorption after orthodontic treatment of traumatized teeth. Am J Orthod. 1982;82(6):487-91. root fracture, concussion, subluxation, luxation, and avulsion. . $^{19,22,23}$

In the present study, $40.25 \%$ of the respondents chose the wrong answers to the questions about orthodontic movement of traumatized teeth. This result indicates that these professionals could take improper procedures when faced with this condition, resulting in undesirable consequences for their patients.

A specific group of orthodontists may not represent the totality of specialists in our country, but can randomly show that an important orthodontic topic such as dental trauma deserves more attention.

Rather than merely exposing the weaknesses revealed by the data collected, our intention was to contribute to the development of practical guidelines related to traumatisms, like those proposed by Flores et al. ${ }^{19,22,23}$ (2007) and Kindelan et al. ${ }^{4}$ (2008), thus rendering the making of clinical decisions less personal or empirical. Furthermore, the emergent shortcomings revealed by this study should be addressed by the programs of specialization courses, and further clarification should be sought by studies following this line of research.

\section{Conclusion}

After analyzing the results, it was possible to conclude that, except for avulsion, the knowledge on dental injuries held by the professionals interviewed was considered unsatisfactory, and about $40 \%$ of them were not acquainted with the recommendations for the orthodontic movement of traumatized teeth.
4. Kindelan SA, Day PF, Kindelan JD, Spencer JR, Duggal MS. Dental trauma: an overview of its influence on the management of orthodontic treatment. Part 1. J Orthod. 2008;35(2):6878.

5. Andreasen JO, Andreasen FM, Andersson L. Textbook and color atlas of traumatic injuries to the teeth. $4^{\text {th }}$ ed. Oxford: Blackwell Munksgaard; 2007.

6. Proffit WR, Fields Jr HW. Ortodontia contemporânea. $3^{\text {a }}$ ed. Rio de Janeiro: Guanabara Koogan; 2002.

7. Phillips JR. Apical root resorption under orthodontic therapy. Angle Orthod. 1955;25(1):1-22. 
8. Wickwire NA, McNeil MH, Norton LA, Duell RC. The effects of tooth movement upon endodontically treated teeth. Angle Orthod. 1974;44(3):235-42.

9. Hines FB. A radiographic evaluation of the response of previously avulsed teeth and partially avulsed teeth to orthodontic movement. Am J Orthod. 1979;75(1):1-19.

10. Turley PK, Joiner MW, Hellstrom S. The effect of orthodontic extrusion on traumatically intruded teeth. Am J Orthod. 1984;85(1):47-56.

11. Spalding PM, Fields Jr HW, Torney D, Cobb HB, Johnson $\mathrm{J}$. The changing role of endodontics and orthodontics in the management of traumatically intruded permanent incisors. Pediatr Dent. 1985;7(2):104-10.

12. Turley PK, Crawford LB, Carrington KW. Traumatically intruded teeth. Angle Orthod. 1987;57(3):234-44.

13. Linge L, Linge OB. Patient characteristics and treatment variables associated with apical root resorption during orthodontic treatment. Am J Orthod Dentofacial Orthop. 1991;99(1):3543.

14. Brin I, Ben-Bassat Y, Heling I, Engelberg A. The influence of orthodontic treatment on previously traumatized permanent incisors. Eur J Orthod. 1991;13(5):372-7.

15. Brezniak N, Wasserstein A. Root resorption after orthodontic treatment: Part 1. Literature review. Am J Orthod Dentofacial Orthop. 1993;103(1):62-6.

16. Brezniak N, Wasserstein A. Root resorption after orthodontic treatment: Part 2. Literature review. Am J Orthod Dentofacial Orthop. 1993;103(2):138-46.
17. Al-Badri S, Kirinons M, Cole BOI, Welbury RR. Factors affecting resorption in traumatically intruded permanent incisors in children. Dent Traumatol. 2002;18(2):73-6.

18. Chaushu S, Shapira J, Heling I, Becker A. Emergency orthodontic treatment after the traumatic intrusive luxation of maxillary incisors. Am J Orthod Dentofacial Orthop. 2004;126(2):162-72.

19. Flores MT, Andersson L, Andreasen JO, Bakland LK, Malmgren B, Barnett F et al. Guidelines for the management of traumatic dental injuries. II. Avulsion of permanent teeth. Dent Traumatol. 2007;23(3):130-6.

20. Kinirons MJ. Treatment of traumatically intruded permanent incisor teeth in children. Int J Paediatr Dent. 1998;8(2):1658.

21. Kugel B, Zeh D, Mussig E. Incisor trauma and the planning of orthodontic treatment. J Orofac Orthop. 2006;67(1):48-57.

22. Flores MT, Andersson L, Andreasen JO, Bakland LK, Malmgren B, Barnett F et al. Guidelines for the management of traumatic dental injuries. I. Fractures and luxations of permanent teeth. Dent Traumatol. 2007;23(2):66-71.

23. Flores MT, Malmgren B, Andersson L, Andreasen JO, Bakland LK, Barnett F et al. Guidelines for the management of traumatic dental injuries. III. Primary teeth. Dent Traumatol. 2007;23(4):196-202.

24. Chrcanovic BR, Freire-Maia B, Souza LN, Araújo VO, Abreu MHNG. Facial fractures: a 1-year retrospective study in a hospital in Belo Horizonte. Braz Oral Res. 2004;18(4):3228. 